\title{
DỨBin
}

Technological University Dublin

ARROW@TU Dublin

\section{Turning to Case Studies as a Mechanism for Learning in Action Learning}

\author{
Denise O'Leary \\ Technological University Dublin, denise.oleary@tudublin.ie \\ Paul Coughlan \\ Trinity College Dublin \\ Clare Rigg \\ University of Liverpool
}

See next page for additional authors Follow this and additional works at: https://arrow.tudublin.ie/tfschhmtart

Part of the Community-Based Learning Commons, Educational Methods Commons, Entrepreneurial and Small Business Operations Commons, Leadership Studies Commons, Operations and Supply Chain Management Commons, Organizational Behavior and Theory Commons, Organization Development Commons, Other Education Commons, Scholarship of Teaching and Learning Commons, and the Service Learning Commons

\section{Recommended Citation}

O'Leary, D.F., Coughlan P., Rigg C. \& Coghlan, D. (2016). Turning to Case Studies as a Mechanism for Learning in Action Learning. Action Learning Research and Practice, vol. 14, no. 1, pp. 3-17. doi:10.1080/ 14767333.2016.1245652

This Article is brought to you for free and open access by the School of Tourism \& Hospitality Management at ARROW@TU Dublin. It has been accepted for inclusion in Articles by an authorized administrator of ARROW@TU Dublin. For more information, please contact arrow.admin@tudublin.ie, aisling.coyne@tudublin.ie, gerard.connolly@tudublin.ie.

Funder: European Union

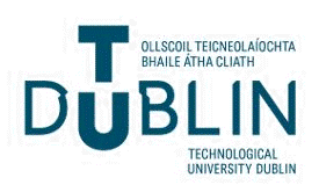


Authors

Denise O'Leary, Paul Coughlan, Clare Rigg, and David Coghlan

This article is available at ARROW@TU Dublin: https://arrow.tudublin.ie/tfschhmtart/72 


\title{
Turning to Case Studies as a Mechanism for Learning in Action Learning
}

\author{
Denise O'Leary, Dublin Institute of Technology, Ireland \\ Paul Coughlan, Trinity College Dublin, Ireland \\ Clare Rigg, Liverpool University, UK \\ David Coghlan, Trinity College Dublin, Ireland
}

Acknowledgements: This work was supported by the European Commission under Grant No. 613776 .

Recommended Citation: O'Leary, D., Coughlan, P., Rigg, C., \& Coghlan, D. (2016). Turning to case studies as a mechanism for learning in action learning. Action Learning: Research and Practice, 1-15. doi:10.1080/14767333.2016.1245652

\section{Abstract}

Case studies are a useful means of capturing and sharing experiential knowledge by allowing researchers to explore the social, organisational and political contexts of a specific case. Although accounts of action learning are often reported using a case study approach, it is not common to see individual case studies being used as a learning practice within action learning sets. Drawing on a network action learning project, this paper explores how the process of coaching, articulating, authoring, sharing and editing case studies provided a vehicle for learning and research within a network action learning set. The intended contribution of this paper to the theory of action learning is to extend the range of learning practices to include the case study within the network action learning set. It discusses how case studies act as boundary objects, which are artefacts that can be used to cross boundaries between groups in order to facilitate learning that might not otherwise occur.

\section{Keywords}

Network action learning, case study, boundary object, boundary spanning, learning

\section{Introduction}

Action learning is a way of thinking and working that exploits the learning that can be gained from focusing on real life problems of personal consequence to learners (Revans 1971). Action learning occurs in an environment where engaging in experimenting, questioning and reflection $(Q)$ is privileged over 'expert' dissemination of programmed knowledge $(P)$. Action learners learn though 
taking action and reflecting with peers on the action, with the aim of improving their own practice. In the process individuals can experience transformation in personal perspectives, in social relations and in perspectives on managing (Rigg and Trehan 2004). Action Learning is an established approach to peer learning with SMEs (small and medium enterprises), employed for the support of SME ownermanagers as well as for policy learning (Ram and Trehan, 2009, 2010).

In this paper we examine how the range of learning practices within action learning sets can be extended to include case studies. There are two fundamental types of case study: research cases and teaching cases. The research case and the associated methodology is a way of addressing a particular kind of research question (Voss 2009). The teaching case is a mechanism for teaching and learning in an applied domain (Leenders and Erskine 1989). There are commonalities between the two: both relate to practice and both present a history of practice. However, there are also differences: the research case is subject to quality standards which enable the research insights to be acknowledged as contributions to theory; while the teaching case is subject to teaching quality standards that enable discussion and reflection upon the story of the case to be acknowledged as contributions to learning. So, although research case studies privilege real life problems over abstract theory, insights generated are codified and abstract in nature and not necessarily meaningful to practitioners in a pragmatic sense. In contrast, teaching case studies focus on the practical over the abstract and thus, insights generated in these practice environments are more pragmatically meaningful.

Although case studies are a useful means of capturing and sharing experiential knowledge by allowing researchers to explore the social, organisational and political contexts of a specific case, entity or phenomenon (Stake 2005), their use generally entails writing or discussion rather than action. This means that it is not common to see individual case studies being used as a learning practice in action learning since, for action learners, the distinction between taking action and talking about taking action is an important one (Revans 1980). Action learning is focused on the learning and development that can be achieved when professionals engage in cycles of reflecting and acting on their own real-life problems in real time. How then can case studies sit comfortably with an action learning approach?

We suggest that research case studies used in the traditional way, to present a theoretical insight based on someone else's real life example, may fit within a philosophy of action learning as programmed knowledge (P) (Revans 1998). Similarly, teaching case studies used in a traditional teaching and learning context, present a concrete story as a form of $\mathrm{P}$ for discussion and reflection. Yet, we want to argue that there is also potential to use the teaching case study in a non-traditional 
way, easily reconciled with a philosophy of action learning. We define case study here as a combination of the rich description of a case writer's real life example, and a discussion note reflecting on that account. Further, we define case study use to encompass both the writing of the case and its employment within a traditional teaching and learning context. Our contribution through this paper is threefold: firstly, to illustrate how the process of case writing creates opportunity for questioning and reflection within an action learning set; secondly to advance the concept of case study as boundary object, with a key role in advancing network learning; and thirdly to illustrate the potential of case study writing as part of an action learning process for evaluation of that action learning.

Since our focus is on highlighting how case studies can sit comfortably with an action learning approach, in the remainder of the paper we first describe the context of the study, we go on to describe how action learning is enacted within the project, we then present the issue of evaluation as an action learning problem and the opportunity for cases studies to contribute a solution, and finally we highlight how case studies can span boundaries to facilitate information sharing within and outside the project.

\section{Context: An Inter-organisational network}

The discussion in this paper is framed within the context of a pan-European project which was conceived with the aim of improving the organisational and innovative practices of small and medium enterprises (SMEs), thus supporting their sustainability. SMEs involved in the project were food production businesses with up to 50 employees. Action learning was both a coordinating and learning mechanism across the project (Shani and Docherty 2008) to facilitate the development of a network made up of SMEs, industry service and technology providers, research institutions, third level education providers, industry representatives and trade organisations. Physically, as illustrated in Figure 1, the network connected nine national centres across eight European countries and joining it gave members access to activities and events such as workshops, conferences and technology transfer events, which over the course of the project, were attended by over 1000 SMEs. Key actors at each centre, or network node, were network learning coaches (NLCs), whose role was to facilitate and enable knowledge and technology transfer both within their national centre and between other national centres through interactions among SMEs. The authors acted as both coordinators of the action learning strategy across the project and as action learning advisors for the NLCs.

As the project progressed and SMEs joined the network and attended events, data was being collected on individual project events and activities. However, as project partners we grappled with 
the issue of how to evaluate the cumulative impact of activities/events on individual SMEs and to find ways to share the learning occurring both within the project network and within action learning sets. Our approach to finding one solution to these issues, namely developing a suite of case studies, forms the focus of this paper.

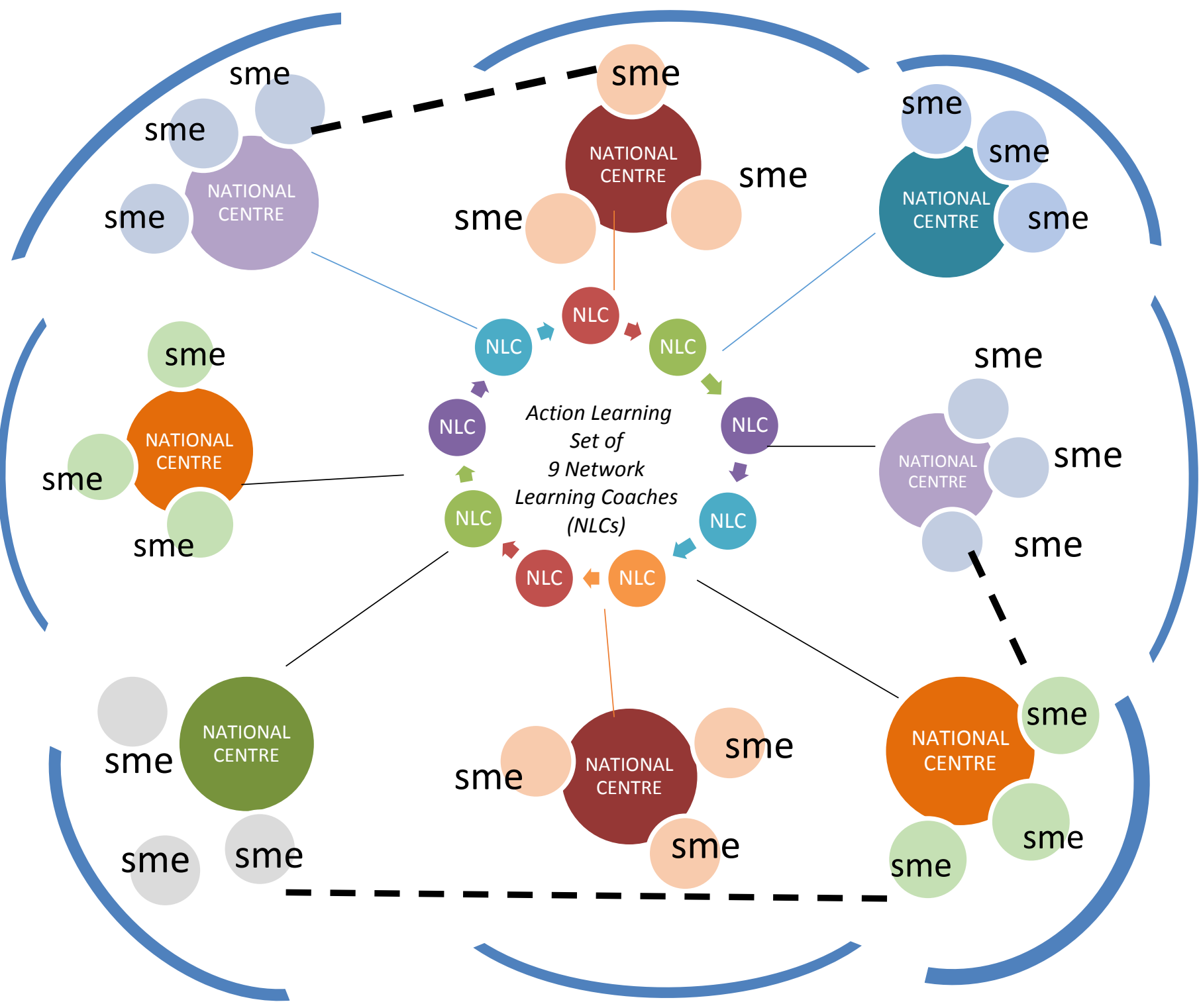

Figure 1: Enacting Principles of Action Learning within the project

Revan's formula $L=P+Q$ is often used to describe the process of learning $(L)$ that occurs in action learning, where $P$ stands for programmed knowledge which is the type of knowledge that exists in books or is known to experts and can be gained from formal instruction, and $Q$ stands for questioning insight, which is the insight gained by asking fresh questions about a problem and reflecting on the responses. Vince (2004) argues that learning does not just occur though an individual's own experience but also through engaging with and collectively reflecting on organizational relations and 
dynamics. He argues that if organisational learning is an aim of action learning, then organising insight $(O)$ must be added to the formula since organisational dynamics can impact on action learning with the reverse also being true. Coughlan and Coghlan (2011) extend the formula yet further to take interorganisational settings, such as the one explored in this paper, into account. The resulting formula is $N A L=P+Q+O+I O$, where NAL is action learning by the network, and $I O$ is insight in an interorganisational context. This formula takes into account the fact that individuals in a network learn both at home, in their own organisational environment, and away, in the network and that learning in each environment can be explored and developed further in the other (Holmqvist 2003). In this project, NLCs dealt with a range of issues at micro and macro level. At a micro level they dealt with organisational challenges such as the technological or business needs of an SME while at macro level there were inter-organisational issues pertaining to the stability, functionality and sustainability of the network. Accordingly, both $O$ and $I O$ were key elements of the action learning principles that underpinned the project.

The project structure can be viewed as comprising of a number of interconnecting subsystems. There was a project network made up of SMEs, researchers, technology and service providers, educators and other stakeholders. Additionally, the project governance structure incorporated individuals in various coordination roles as well as a steering committee. Finally, as illustrated in Figure 1, at each of the national centres, there was at least one network learning coach (NLC) who was both a project partner and a staff member of a research or third level educational institution. These NLCs were key individuals who spanned boundaries between the different subsystems of the network, national centres and project governance structure and in doing so, linked them (Coghlan, Rashford, and Neiva de Figueiredo 2016). It has been previously highlighted that such linkages can be achieved though boundary spanning activities which can be divided into three main categories: representation, co-ordination of task performance and general information searching (Marrone 2010). In undertaking representation, boundary spanners advocate for the group by negotiating for support for group decisions and looking for feedback on group activities. Co-ordination of task performance involves interaction with others in order to achieve the goals of the group. General information searches are those which involve seeking knowledge and expertise from outside the group. The role of the NLCs included all of these activities. They acted as the point of contact for SMEs in their region who wished to join the network and they liaised on a one-to-one basis with these SMEs to explore how they could advocate for the SMEs and ensure that their needs could be met by the project. They identified productive partnerships and initiated relationships across the network between individual SMEs and also between SMEs and other network members such as technology suppliers and researchers. Additionally they maintained relationships with each other and interacted 
with the project governance structures to ensure that the network functioned as an integrated network rather than as nine individual national centres. They were also responsible for organising and finding expertise for project events and activities.

The NLCs made up an action learning set, meeting physically and virtually at regular intervals to share concerns, experiences and reflections. Our role (the authors) was as action learning advisers/facilitators for the set to assist set members to learn with and from each other, to facilitate their boundary spanning activities and support the enactment of $N A L=P+Q+O+I O$.

\section{A shared network action learning problem: Evaluation as an example}

Revans (1982) distinguished between puzzles and problems and suggested that problems should be the focus of action learning. Puzzles are issues that can be clearly defined and dissected and a right or wrong solution can be found. Problems on the other hand are those intractable and messy issues that are complex and dynamic, have no one solution, may not be clearly defined and are often closely connected to other issues in ways that are difficult to identify. Action learning holds particular value for combining both individual learning and organisational benefits for those focusing on problems (Edmonstone 2015). Revans captured this interplay of individual and organisational learning in his three systems theory of learning: alpha, beta and gamma. System alpha is focused on the investigation of a problem, taking contextual elements into account such as the managerial value system, internal resources and the external environment. System beta is concerned with addressing the problems in successive cycles of planning, taking action, reflecting on action and learning. System gamma emphasises the personal learning gained through interaction with systems alpha and beta (Revans 1971)

NLCs encountered both puzzles and problems, related to the SMEs they worked with, with their own role and related to the development of the network. It was our experience that although puzzles were brought to set meetings by NLCs, these were quickly solved and it was with addressing problems that the set occupied itself. A shared concern within the project from the outset was how project progress and outcomes might be evaluated and the NLC action learning set took this up. This was a problem rather than puzzle, not only because of the complexities of the project, but also because of the complexities involved in evaluation itself.

With regard to the complexity of the project, there were a range of developmental events and activities occurring on an on-going basis across all nine national centres. These include training workshops, networking events and information days. SMEs had the choice of engaging with as many 
or as few of these activities as they wished. As well as evaluating single events, project partners were expected to evaluate the cumulative impact of participation in the project on individuals and firms who engaged with project activities to lesser or greater degrees. Thus, evaluation had to focus not only on individual development, but also on organisational and inter-organisational development. This brought with it the challenge of making sense of the interactions between individual and organisational learning which are inextricably intertwined (Rigg 2008) and the added challenge of making sense of those relationships in the context of a network (Provan and Sydow 2008).

There is also complexity involved in evaluating any initiative, as detailed by Edmonstone (2015). When to evaluate can be a nuanced decision as it can be difficult to time the evaluation of learning that is intended to have long term rather than short term impacts. It can also be difficult to define what success actually means, due to different individual expectations. Finally, evaluation can be both costly and political and it can be a struggle to match the size and complexity of evaluative mechanisms to a project.

\section{How to Evaluate: Why is it a problem?}

There is a significant dearth of theory on evaluating interorganisational networks and no consensus on how best to approach it from a practical perspective. Provan and Sydow (2008) highlight that from an epistemological perspective, evaluation underpinned by positivism is the most common approach to evaluation at an interorganisational level, but that this type of evaluation has been criticized as it does not take account of context. They note that participative and collaborative approaches to evaluation are becoming more common. These approaches allow for formative learning as evaluation efforts can have an immediate impact on the development of a network and they also capture more effectively the contextual and political nuances at play. However, there is limited guidance available on how to undertake such evaluation, thus it falls to researchers to determine the epistemological and methodological choices appropriate to their needs.

Evaluation can focus, singly or in combination, on the structure, process and outcome of interorganisational relations. Because this project was underpinned by action learning as both a coordination and learning mechanism, focusing on the process of learning and the resultant outcomes was deemed the most appropriate approach to evaluation. However, evaluation at interorganisational level should not exist in a vacuum and should be closely linked to evaluation of organisations involved (Provan and Sydow 2008). Similarly, organisations are made up of people, and in this project, it is individuals from each organisation that make up the network, either, as in the case of SMEs as participants in workshops and other events, or, as in the case of NLCs, members of an action learning set and the organisers of SME events. Thus, evaluating interorganisational learning, 
necessitated an examination of learning at the level of the different units that made up the network: individuals, organisations and the network itself.

But what does evaluation of learning mean? Kirkpatrick and Kirkpatrick (2006) have previously highlighted the importance of evaluation at four levels: participant reactions to an event/activity; learning gained as a result of participation; behavioural change; and organisational results. The first three examine learning from the perspective of individuals, and the fourth from an organisational perspective. It is relatively uncomplicated to assess individual participant reactions to a particular event or activity and it is also possible to assess learning However, assessing the application of that learning, in other words, behavioural changes or organisational changes, is more difficult. There are characteristics related to the participant, the organisational environment and the design of the event and that impact learning and the application of learning in practice (Mavin, Lee, and Robson 2010). Therefore, in moving up the levels of evaluation from participant reaction to organisational results, it becomes increasingly difficult to assign cause and effect (Kirkpatrick and Kirkpatrick 2006). How could we know if sales increases or product innovation were directly the consequence of the SME owner attending a particular event, rather than being the result of a constellation of factors?

Evaluating inter-organisational learning and outcomes poses additional challenges. . Establishing causal links in an inter-organisational context is even more complex than establishing them at individual and organisational level as it can be difficult to attribute outcomes to involvement in a network and to distinguish them from outcomes that may have occurred anyway (Provan and Sydow 2008). Complexity is also increased by the existence of various factors that can influence interactions between individuals from different backgrounds such as trust and power ( $O^{\prime}$ Leary 2016). This can impact on network processes and outcomes and may also affect decisions on who should be involved in evaluation. Provan and Sydow (2008) suggest that collaborative evaluation involving a range of stakeholders from a network is helpful in evaluation at an inter-organisational level. Within this project, action learning provided the epistemological basis and the vehicle through which such collaborative evaluation could occur. By this we mean that the action learning set became a vehicle for evaluation of the project through NLCs taking on the task of preparing case studies of SME experiences, while at the same time, the process of sharing of these cases facilitated network building and learning. We elaborate on this in the next section and describe how the praxeology of action learning, captured by Revans' (1971) systems of alpha beta and gamma was enacted in the case study writing and sharing process. 


\section{The Intervention: Case Study Development using an Action Learning Approach}

The NLCs collaborated in the development of over 20 case studies. As a set, the case studies held significant potential for the development of each NLC's knowledge of improvement opportunities in the firms and their role in facilitating the realisation of those opportunities. The unit of analysis was the firm, the voice was that of the SME participant in the project. Each case was a rich description of the practice and context within which the firm operated and told the particular story of the firm. Each case was built on data, based upon the experience of the firm as told by the firm through one or more interviews conducted by a NLC. The data included the particular background, history, challenges of the firm and their engagement in the project. The challenges ranged from maintaining regional identity in a nationally competitive context to codifying operational practices in order to maintain certification to produce. Proprietary data was excluded. As a set, the case studies were comparable in that multi-dimensional and comprehensive insights emerged in relation to the challenges faced by the firms and the impact of their participation in the project.

Revans' (1971) praxeology of three interacting systems of alpha, beta and gamma underpinned NLC set meetings. As an example of system alpha, the complexity of evaluation of the network was identified through reflection, critical questioning and discussions both within the NLC action learning set and outside it. NLCs were already gathering data directly on participant reactions and participant learning during project events. However, behavioural changes, organisational learning and inter-organisational learning were not being captured. Development of case studies were adopted by set members as a potential solution to the problem.

System beta, the problem solving stage, involved an intervention in six parts:

1. Development of case-writing guidelines by the set advisers (the authors) after a NLC learning set discussion on the topic.

2. Briefing of the network learning coaches followed by discussion and critical evaluation within set meetings to clarify the use of the guidelines.

3. Cycles of case writing by the NLCs. They engaged with SMEs in an action learning way by meeting them at home in the national centre to engage in mutual questioning and critical reflection to explore what the firm was trying to achieve, how they had engaged with the project, what learning had occurred and what impact this had at a personal, organisational and inter-organisational level. The case studies were then introduced away in the network in action learning set meetings where a further 
process of critical reflection, facilitated by the set advisers, led to editing and refining. This initiated further cycles of reflection at home where the SMEs and NLCs examined the refinements and developed the case further.

4. Presentation by the network learning coaches of their cases at a project meeting as a basis for discussion among project partners on the performance of the project against its objectives.

5. Sharing the cases with other project partners.

6. Use of the cases by the network learning coaches in workshops and technology transfer events and dissemination of the cases on the project website through newletters.

System gamma, the personal learning of participants, was enacted for SMEs in the case writing and critical questioning of their practice through their engagement with NLCs. For NLCs, it was enacted through the process of engaging with SMEs, writing the cases and critically questioning not only their own case but those written by the other NLCs.

Although this paper is not concerned with the content of the case studies, rather with the process of their writing and use as a learning mechanism, for illustration purposes we include a summary of an SME participant case in Figure 2. To explore the enactment of action learning through the case study we also include reflections of the NLC who co-created the case with the SME. 


\section{SME illustration}

One of the SMEs who had set up a niche bakery reported on her experience: she attended workshops in Ireland, Germany and Italy on competitiveness, cost models, pricing strategies, scaling the business, distribution channels, supply chain and distribution networks. She highlighted that engagement in the network allowed her time to reflect and plan. "Participation has allowed me to pull back from the day to day, hearing stories of other food producers". She reported that her engagement enhanced her networking skills and she learned to reach out to businesses in other sectors. "It reaffirmed my confidence in the value of my knowledge". Taking part in network activities also helped her develop her ideas on various business models and ideas for expansion.

\section{Network Learning Coach Reflection}

"By co-developing the case study, I learned about the internal dynamics of the SME and how the network could help the owner. Then, by unpicking the case with the other NLCS, I gained a greater understanding of how I could support SMEs in a practical way. I was struck by how the issues faced by the SME owner in my case resonated with the other NLCS. By talking though all the cases in set meetings we could see that there were commonalities in the problems facing many of the SMEs in the network. By listening to the experiences of other NLCS, I also learned how to forge connections with the SMEs in my national centre and learned more about the kinds of questions I could use to help them to frame the problems that they faced. This case-based shared experience fed into the design of national and network events and workshops, helped us to assess and reassess the aims of the network and how to address them, helped strengthen my relationships with other NLCs and compare their experiences at their national centres to mine."

Figure 2: Reflections of an SME and NLC

\section{Summary: Action learning systems alpha, beta and gamma as network learning evaluation}

In this project, case writing was a mechanism by which the experience of the firms within the national centres could be articulated in terms of their experience within their respective industry and local market (system alpha), their engagement in the project network with the programmed events and with the NLCs and other like firms (system beta) and their own learning (system gamma). Guidelines were issued which offered guidance on how a case could be selected, how data could be gathered and how the case could be written and used, but did not impose a tightly defined process or 
final case structure. The NLCs responded enthusiastically to the resonances created by the cases. They supported one another over the period of the case-writing and demonstrated at set meetings the perceived potential of the cases as capturing the core of the action learning process for them in their role as network learning coaches.

As captured in table 1, and highlighted by the reflections in Figure 2, in contrast to their traditional use, the case studies did not function as static objects to be used outside their context. Instead the process of developing case studies was used as a stimulus to NLCs and SMEs to question and reflect upon their practices with a view to learning and applying that learning. Additionally, by using action learning in evaluation, space and time was created within the NLC set to: explore and critically assess project aims; to evaluate whether and how we were meeting them; and investigate the more appropriate aims on which to focus. All of this activity led to learning and subsequent action at personal, organisational and inter-organisational levels. Table 1 summarises this in terms of the formula $N A L=P+Q+O+I O$.

\begin{tabular}{|c|c|c|c|}
\hline \multirow[t]{3}{*}{ Perspective } & \multicolumn{3}{|c|}{ Phase } \\
\hline & \multirow[t]{2}{*}{ Cycles of Case writing } & \multicolumn{2}{|c|}{ Case Usage } \\
\hline & & $\begin{array}{l}\text { in Evaluating Project Processes } \\
\text { and Outcomes }\end{array}$ & $\begin{array}{l}\text { in Project Workshops and } \\
\text { Events } \\
{\text { (If applicable }{ }^{1} \text { ) }}^{\text {If }} \text {. }\end{array}$ \\
\hline $\begin{array}{l}\text { SME - subject } \\
\text { of the case }\end{array}$ & $\begin{array}{l}\text { - } \quad \text { : little overt theory } \\
\text { Q: the questioning and } \\
\text { reflection on the practice } \\
\text { and experience of the firm } \\
\text { O: questioning and } \\
\text { reflecting to make sense of } \\
\text { the organisational } \\
\text { dynamics within their firm } \\
\text { that constrained or aided } \\
\text { their attempts at change } \\
\text { IO: insight on their } \\
\text { interactions with the } \\
\text { project network }\end{array}$ & $\mathrm{N} / \mathrm{A}$ & $\begin{array}{l}\text { - P: the case itself } \\
\text { Q: the questioning and } \\
\text { reflection on the practice } \\
\text { and experience of the } \\
\text { firm led by the discussion } \\
\text { facilitator and the other } \\
\text { SMEs } \\
\text { O: articulating the } \\
\text { organisational dynamics } \\
\text { within their firm that } \\
\text { constrained or aided their } \\
\text { attempts at change } \\
\text { IO: insight on their } \\
\text { interactions with other } \\
\text { SMEs at the events }\end{array}$ \\
\hline
\end{tabular}

\footnotetext{
${ }^{1}$ Thus far one SME has presented her case at a project event. It is envisioned that others will do the same.
} 


\begin{tabular}{|c|c|c|c|}
\hline & $\begin{array}{l}\text { - } \mathrm{L} \text { : the insights which } \\
\text { emerge from engaging in } \\
\text { the telling of the story to } \\
\text { the case writer }\end{array}$ & & $\begin{array}{l}\text { - L: the insights which } \\
\text { emerge from engaging in } \\
\text { the telling of and } \\
\text { reflection on the story to } \\
\text { other firms }\end{array}$ \\
\hline $\begin{array}{l}\text { Network } \\
\text { Learning Coach } \\
\text { - writer of the } \\
\text { case }\end{array}$ & $\begin{array}{l}\text { - P: a sense of what theory } \\
\text { might be useful in the } \\
\text { discussion guide } \\
\text { Q: the questioning and } \\
\text { reflection on the practice } \\
\text { and experience of the firm } \\
\text { O: gaining a deeper } \\
\text { understanding of the } \\
\text { organisational relations at } \\
\text { the firm } \\
\text { IO: gaining greater insight } \\
\text { on activities across all } \\
\text { national centres in the } \\
\text { network } \\
\text { L: the insights which } \\
\text { emerge from engaging in } \\
\text { gathering the data and } \\
\text { writing the story of the } \\
\text { firm }\end{array}$ & $\begin{array}{l}\text { P: a sense of what theory } \\
\text { might be useful in future } \\
\text { project activities and } \\
\text { events } \\
\text { Q: the questioning and } \\
\text { reflection on the practice } \\
\text { and experiences at each of } \\
\text { the national centres } \\
\text { O: gaining a deeper } \\
\text { understanding of the } \\
\text { organisational relations } \\
\text { and dynamics at their } \\
\text { national centre } \\
\text { IO: questioning and } \\
\text { reflecting on interactions } \\
\text { with other NLCs and } \\
\text { project stakeholders and } \\
\text { the impact on the project } \\
\text { progress } \\
\text { L: the insights which } \\
\text { emerge from evaluating } \\
\text { project progress }\end{array}$ & $\begin{array}{l}\text { P: application of theory to } \\
\text { help with the positioning } \\
\text { of the experience of the } \\
\text { firm } \\
\text { Q: the questioning and } \\
\text { reflection on the practice } \\
\text { and experience of the } \\
\text { firm led by the discussion } \\
\text { facilitator and the other } \\
\text { SMEs } \\
\text { O: gaining a deeper } \\
\text { understanding of the } \\
\text { organisational relations } \\
\text { and dynamics at their } \\
\text { national centre } \\
\text { IO: questioning and } \\
\text { reflecting on the project } \\
\text { network and interactions } \\
\text { with other NLCs and } \\
\text { project stakeholders } \\
\text { L: the insights which } \\
\text { emerge from engaging in } \\
\text { the questioning and } \\
\text { reflecting on the story } \\
\text { with other firms }\end{array}$ \\
\hline
\end{tabular}

Table 1: Enactment of Action Learning in the Process of Case Development

\section{Discussion: Case Studies as Boundary Objects to Extend Learning beyond the Set}

Argyris highlights that organisational learning is promoted through the sharing of valid information, which is information relating to an issue that is relevant and meaningful to others (Dixon 2014). This idea is echoed and extended in the open innovation literature, which suggests that firms must go beyond their own boundaries to access such information (van deVrande et al. 2009). Traditionally in action learning, there is no commitment to extend learning gained beyond the set (Coghlan and Coughlan 2010). As a result, action learning has sometimes criticised for the fact that learning can become bounded within a single organisation or within a single action learning set, in contrast to other action modalities such as action research which involves sharing knowledge to a wider community (Raelin 2009). This paper highlights how such criticism can be address through the use of case studies as boundary objects. 
Earlier we introduced the concept of boundary spanning and illustrated how, in the context of this project, NLCs act as boundary spanners across project subsystems. Boundary spanning can also occur through the use of boundary objects, understood as objects which can be used to cross boundaries for example reports, web pages, information technology systems and procedural manuals (Heldal, 2010). In the language of action research, boundary objects are articulated units of $P$ (programmed knowledge).

Levina and Vaast (2005) suggest that some boundary objects are designated boundary objects; in other words they are deliberately designed to span different boundaries. Others are created for some specific use by one group or another and only emerge as boundary objects when put to use by other groups. In the example of action learning discussed in this paper, the development of case studies was conceived as a means of evaluating project progress and not specifically as a means of spanning boundaries. However, as Edmonstone (2015) suggests, action learning facilitates the process of creating explicit knowledge from tacit knowledge. This process was enacted in the project as the tacit knowledge and experience of SMEs was articulated as explicit knowledge in the case studies, providing the case studies with an emergent function as boundary objects.

Boundary object capability is manifested in a number of ways. Firstly the case studies provided the NLCs with a window into activities at each of the other national centres. Accordingly, the case studies allowed inter-project boundaries between countries and national centres to be spanned, leading to the NLCs making changes at their own national centres based on the experiences of other NLCs and SMEs at other national centres. Secondly, they provided P, in the form of teaching case studies that were used in other project events, such as workshops, to stimulate $Q$. In this way they facilitated $\mathrm{O}, 1 \mathrm{O}$ and therefore network action learning (NAL) according to the formula: $N A L=P$ (programme knowledge) $+Q$ (questioning insight) $+O$ (organising insight) $+I O$ (inter-organisational insight). Thirdly, codifying SMEs narratives into case studies provided a means of creating a repository of information for use by NLCs. As highlighted by Gearty (2015), learning is something that may not occur in the moment that an individual hears a narrative; instead there is potential that the learning may occur at another time. Providing ongoing access to the case studies exploits this potential.

A final means by which the case studies acted as boundary objects is through their dissemination via the project website. We cannot assume that the information in the cases can be directly applied by other SMEs, as one of the underpinning principles of action learning is that all problems are contextual and therefore solutions in one context may not be directly applicable in another (Burgoyne 2010). However, there is the potential created through dissemination across the 
project boundary, for this programmed knowledge to stimulate learning and insight. As a result, SMEs who were not directly involved in project events and activities can still benefit from them.

\section{Conclusion - Our learning}

There is no single 'correct' approach to action learning and over the past several decades, different variations have been developed (Gold 2014). In this paper we suggest that the process of developing case studies can be a useful learning mechanism for the action learner in three ways:

1. the process of case writing creates opportunity for questioning and reflection within an action learning set;

2. as a means of evaluation as part of a network action learning process and;

3. to advance the concept of case study as boundary object, with a key role in advancing network learning.

In relation to the first, a key aspect of action learning is creating the potential to act and therefore to learn from the process of acting (Gold 2014). For the NLCs, acting included cycles of case writing and refining, supported by the other NLCs in the set. This occurred in cycles of reflection on action away at NLC set meetings leading to action at home in the national centres. The process of engaging in case study writing prompted reflection for NLCs on the experiences of firms, on their own experiences at their national centres and on network level interactions with other NLCs and network stakeholders, highlighting that the process of case writing can be used as a learning practice within action learning sets. Developing case studies also prompted critical insight on the part of SME participants as they were facilitated by the NLCs to reflect on any learning and action that resulted from their engagement with $P$ and $Q$ during network events and how that impacted on the organisational relations at their firm and their relations with others within the network.

The multilevel focus on individual, firm and network described above is important in light of our second argument that case study development can be used as a means of evaluation in network action learning. Revans' initial focus in using action learning was on individual learning. However, it has been argued that a concurrent focus on organisational learning is appropriate in action learning interventions (Vince 2004) and a growing body of literature on organisational learning provides a theoretical base for this focus (Bapuji and Crossan 2004). Additionally, in networks organisational learning is interwoven with inter-organisational learning and it is problematic to try to consider one without the other (Holmqvist 2003). The aim of the network described in this paper was to develop the capacity of individuals and organisations to adapt to change and to collaborate towards improving 
their organisational practices. The network was a loosely coupled network and the project was a complex one, making evaluation difficult. However, developing case studies allowed NLCs to focus on a few firms at their national centre and to examine in detail what sort of impact membership of the network had on those firms. We noted previously that network action learning does not only depend on $\mathrm{P}$ and $\mathrm{Q}$ but must also take $\mathrm{O}$ and $\mathrm{IO}$ into account. By taking part in case study development, both SMEs and NLCs could develop organising insight through examining and reflecting on organisational dynamics at their places of work (Vince 2004). For SMEs this organisational insight related to the internal dynamics of their firms while for NLCs it also included insight on the dynamics within the national centres. Both SMEs and NLCS also gained inter-organisational insight by focusing on how the firms had engaged with the network, what differences in terms of learning and outcomes that made both to the firm and the network, how they might engage differently in the future (SMEs) and how SMEs might be facilitated to do that (NLCs). Thus, internal organisational dynamics and the broader social context were both taken into account. Additionally, there was a concurrent focus on personal learning, organisational learning and inter-organisational learning. The literature on interorganisational learning is limited and accordingly does not offer much guidance on how to evaluate inter-organisational initiatives (Provan and Sydow 2008). We suggest that developing case studies through action learning is both pragmatic and participative and can be one way of addressing this gap.

In relation to evaluation, we also argue that creating case studies using action learning can provide a means of reflecting on the evaluation process itself. Burgoyne (2010) notes that there is an issue with evaluation which is instrumental in nature and focuses on testing the achievement of aims rather than critically questioning and challenging those aims. He suggests that "Science can find out if A can lead to B, but cannot establish whether B is a good thing or not" (Burgoyne 2010, 247). However, by using action learning in evaluation, space and time is created to enable a critical exploration of project progress and the appropriateness of project aims. This suggests that evaluation carried out in this way brings with it the potential to develop double loop rather than single loop learning. Single loop learning is that which is achieved from a goal driven focus where the immediate issue is addressed without necessarily addressing the underlying cause, while double loop learning results in changed assumptions, values and goals and addresses underlying issues (Argyris and Schön 1974). By engaging in case study development, NLCs were facilitated to explore the actual and potential impact of the network on individual firms. This in turn lead to double loop learning as the experiences of the firms in question impacted on the prior assumptions that the NLCs had made about SMEs as well as their views on the best way to address SME issues.

The third conclusion we draw is that a case study can be viewed as a boundary object that facilitates boundary spanning both in terms of the process of case writing and as a finished product. 
Boundary spanning can be a means by which organisational practices are shaped by network membership and networks are shaped by organisational interactions (Marrone 2010). This occurred during the project. During case study development, SME owners were encouraged to articulate the changes they introduced at organisational level, the understanding they developed of their own organisational environment and their interaction with network stakeholders. Accordingly, NLCs were able to adapt network practices and the design and delivery of network activities to better match the needs of SMEs.

Additionally, as has been highlighted in the open innovation literature, firms that look only inwards and do not utilise the knowledge and experience of other firms put themselves at risk of stagnation (Lee et al. 2010). Yet, sometimes tacit information can be difficult to share. Boundary objects are a means of making tacit knowledge more explicit. In this paper we have described the development of case studies where each case tell the story of the SME and their particular engagement with the project network. Additionally, as a set, the case studies are comparable so that a rich picture emerges of the range of firms and experiences in the project. This richness is of value in its articulation of the potential and firm-level impact of the project, as a respectful non-directive means of sharing the experiences of SMEs with others as well as building up a picture of the emergent network. Thus, the set of case studies has become a repository of codified tacit knowledge and experience, useful to NLCs, SMEs and project stakeholders.

\section{References}

Argyris, C. \& D.A. Schon. 1974. Theory-in-practice: Increasing Professional Effectiveness. San Francisco: Jossey-Bass.

Bapuji, H., and M. Crossan. 2004. "From Questions to Answers: Reviewing Organisational Learning Research." Management Learning, 35(4): 397-417.

Burgoyne, J.G. 2010. "Evaluating Action Learning: A Critical Realist Complex Network Theory Approach." Action Learning: Research and Practice, 7(3): 239-251.

Coghlan, D., P. Coughlan, and L. Brennan. 2004. "Organizing for Research and Action: Implementing Action Researcher Networks." Systemic Practice and Action Research, 17 (1): 37-49.

Coghlan, D., and P. Coughlan. 2010. "Notes Towards a Philosophy of Action Learning Research." Action Learning: Research and Practice, 7(2): 193-203.

Coghlan D., and M. Pedler. 2006 "Action Learning Dissertations: Structure, Supervision and Examination." Action Learning: Research and Practice. 3(2): 127-139. 
Coghlan, D., N.S. Rashford, and J. Neiva de Figueiredo. 2016. Organization Change and Strategy. $2^{\text {nd }}$ ed, Routledge: Abingdon.

Coughlan, P., and D. Coghlan. 2011. Collaborative Improvement through Network Action Learning. Cheltenham: Edward Elgar.

Dixon, N. 2014. "Argyris and Revans on Holding Meaningful Conversations" Action Learning: Research and Practice, available online at http://www.tandfonline.com/doi/full/10.1080/14767333.2014.945786

Edmonstone, J. 2015. "The Challenge of Evaluating Action Learning." Action Learning: Research and Practice, 12(2): 131-145.

Gearty, M. 2015. "Beyond You and Me: Stories for Collective Action and Learning? Perspectives from an Action Research Project." Action Learning: Research and Practice, 12(2): 146-165.

Gold, J. 2014. "Revans Reversed: Focusing on the Positive for a Change." Action Learning: Research and Practice. 11(3): 264-277.

Heldal, F. 2010. "Multidisciplinary Collaboration as a Loosely Coupled System: Integrating and Blocking Professional Boundaries with Objects." Journal of Interprofessional Care, 24(1): 19-30.

Holmqvist, M. 2003. "A Dynamic Model of Intra- and Inter-Organizational Learning." Organization Studies, 24(1): 95-123.

Kirkpatrick, D.L., and J.D. Kirkpatrick. 2006. Evaluating Training Programs: The Four Levels, 3rd ed. San Francisco: Berrett-Koehler.

Lee, S., G. Park, B. Yoon and J. Park. 2010. "Open innovation in SMEs - An intermediated network model." Research Policy, 39: 290-300.

Leenders, M.R., and J.A. Erskine. 1989. Case Research: The Writing Process. School of Business Administration: The University of Western Ontario.

Levina, N., and E. Vaast. 2005. "The Emergence of Boundary Spanning Competence in Practice: Implications for Implementation and Use of Information Systems." Management Information Systems Quarterly 29(2): 335-363.

Mavin, S., L. Lee, and F. Robson. 2010. "The Evaluation of Learning and Development in the Workplace: A Review of the Literature." Bristol: Higher Education Funding Council for England.

Marrone, J.A. 2010. "Team boundary spanning: A multilevel review of past research and proposals for the future." Journal of Management, 36(4): 911-940.

O'Leary, D.F. 2016. "Exploring the Importance of Team Psychological Safety in the Development of Two Interprofessional Teams." Journal of Interprofessional Care, 30(1): 29-34.

Provan, K.G. J. and Sydow. 2008. "Evaluating Inter-organizational Relationships" In The Oxford Handbook of Inter-Organizational Relations, edited by S. Cropper, C. Huxham, and M. Ebers, 691716. Oxford: Oxford University Press. 
Raelin, J. 2009. "Seeking Conceptual Clarity in the Action Modalities." Action Learning: Research and Practice, 6 (1): 17-24.

Ram, M. \& Trehan, K. 2010. Critical action learning, policy learning and small firms: An inquiry Management Learning 41(4):415-428

Ram, M. \& Trehan, K. 2009. Critical by design: enacting critical action learning in a small business context. Action Learning Research and Practice 6(3):305-318

Revans, R.W. 1998. "Sketches in Action Learning." Performance Improvement Quarterly, 11(1): 2327.

Revans, R.W. 1982. The Origins and Growth of Action Learning. Bromley: Chartwell-Bratt.

Revans, R.W. 1980. Action Learning: New Techniques for Management. London: Blond \& Briggs. Revans, R.W. 1971. Developing Effective Managers. London: Longman.

Rigg, C. 2008. Action learning for organisational and systematic development: towards a "both and" understanding of "I and we". Action Learning: Research and Practice, 5 (2): 105- 116.

Rigg, C. and Trehan, K. 2004 Reflections on Working with Critical Action Learning, Action Learning: Research and Practice, 1 (2), 149-166.

Shani, A. B. (Rami) and Docherty, P. 2008 "Learning by Design: Key Mechanisms in Organization Development". In Handbook of Organization Development, edited by T. Cummings, 499518.Thousand Oaks: Sage.

Stake, R. E. (2005), "Qualitative case studies," in The Sage Handbook of Qualitative Research (3rd ed.), edited by N. K. Denzin and Y. S. Lincoln, 433-466, Thousand Oaks, CA: Sage Publications.

van de Vrande, V., de Jong, J. P. J., Vanhaverbeke, W., and de Rochemont, M. 2009. "Open Innovation in SMEs: Trends, Motives and Management Challenges." Technovation, 29(6-7): 423-437.

Vince, R. 2004. "Action Learning and Organizational Learning: Power, Politics and Emotion in Organizations." Action Learning: Research and Practice, 1(1): 63-78.

Voss, C. 2009. "Case Research in Operation Management" In Researching Operations Management, edited by C. Karlsson, 162-195. Abingdon: Routledge.

\section{Note on Contributors}

Dr Denise O'Leary is the Assistant Head of School of Hospitality Management and Tourism at Dublin Institute of Technology. She has over 20 years of international experience in research and consulting and has worked with numerous public and private sector organisations on aspects of organisational change, teamwork and interorganisational collaboration. She is particularly interested in action research and action learning as research approaches. 
Prof Paul Coughlan is Professor in Operations Management at the Trinity Business School, Trinity College Dublin, Ireland. His research interests include continuous improvement of manufacturing and product development practices, action learning and action research. His co-authored book with David Coghlan, Collaborative Strategic Improvement through Network Action Learning: The Path to Sustainability, was published by Edward Elgar (2011).

Dr Clare Rigg is senior lecturer at the University of Liverpool School of Management, where she supervises doctoral practitioners for the DBA.

Prof David Coghlan is a Professor Emeritus and Fellow Emeritus at the Trinity Business School, Trinity College Dublin, Ireland. He is co-author of: Collaborative Strategic Improvement through Network Action Learning (Edward Elgar, 2011) and Organizational Change and Strategy $\left(2^{\text {nd }}\right.$ ed. Routledge, 2016) and is co-editor of The Sage Encyclopedia of Action Research (2014). He serves on the editorial advisory boards of several journals, including Action Learning: Research and Practice. 